\title{
Parent's Knowledge on Rotavirus Diarrhea and Vaccine in Indonesia
}

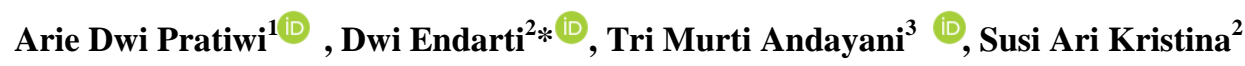 \\ ${ }^{1}$ Master Program in Pharmacy Management, Faculty of Pharmacy, Universitas Gadjah Mada, Indonesia. ${ }^{2}$ Department of \\ Pharmaceutics, Faculty Pharmacy, Universitas Gadjah Mada, Indonesia. ${ }^{3}$ Department of Phamacology and Clinical Pharmacy, \\ Faculty Pharmacy, Universitas Gadjah Mada, Indonesia.
}

\begin{abstract}
A R T IC LE IN F O
A B S T R A C T

Original Article

VacRes, 2020

Vol. 7, No. 1, 38-43

Received: June 15, 2020

Accepted: August 23, 2020

Pasteur Institute of Iran

*Corresponding Author: Dwi

Endarti; Departement of

Pharmaceutics, Faculty Pharmacy,

Universitas Gadjah Mada. Indonesia

Email: endarti_apt@ugm.ac.id

Tel/Fax: $(+62) 274543120$

KEYWORDS: Health literacy, Rotavirus diarrhea, Rotavirus vaccinepathogens; coronaviruses; COVID-19

Introduction: Parent's knowledge on rotavirus diarrhea and vaccine might influence the decision to vaccinate a child. The purpose of this study was to examine knowledge level and to determine the factors that influence parents' knowledge on rotavirus diarrhea and vaccine. Methods: The study applied an observational study design with a multi-center cross-sectional approach. The research instrument used a questionnaire to determine the sociodemographic variables and knowledge of respondents. Results: Data were collected from a survey of 500 parents in 5 provinces including Province of Central Kalimantan, Lampung, Central Sulawesi, West Java, and Yogyakarta in Indonesia using convenience sampling technique. Parents' knowledge in this study was quite good with the average score of $78.2 \pm 16.81$. However, out of 500 respondents, only $158(31.6 \%)$ parents knew that the rotavirus vaccine was not included in Indonesia's national health insurance program. There was a significant difference in the average of knowledge between the characteristics groups of age, education, monthly expenditure and experience of hearing diarrhea and rotavirus vaccine, vaccinating and source of disease information and vaccine ( $\mathrm{p}<0.05$ ). Conclusion: This study suggests the need of health promotion related to rotavirus diarrhea and vaccine in order to achieve equitable distribution of information and increase public knowledge to support future immunization programs.
\end{abstract}

\section{Citation:}

Pratiwi A D, Endarti D, Andayani T M, Kristina S A. Parent's Knowledge on Rotavirus Diarrhea and Vaccine in Indonesia. vacres. 2020; 7 (1) :38-43. DOI: 10.29252/vacres.7.1.38

\section{INTRODUCTION}

Rotavirus is a common cause of diarrhea in children [1]. Rotavirus diarrhea is usually characterized by vomiting, fever and severe dehydration [2] which usually attacks children under 2 years old [3]. Rotavirus diarrhea might results in severe lifethreatening dehydration if not treated immediately hence needs inpatient therapy and administration of intravenous fluids [4]. Distinguishing diarrhea and rotavirus diseases from other diarrheal diseases is difficult because there are many infections in Indonesia that cause diarrhea; hence they need laboratory tests for confirmation. The incidence of diarrhea in 2018 in the province of West Java was 46.35\%; Central Sulawesi $44.84 \%$; Central Kalimantan 36.12\%; Lampung 33.21\%; and Yogyakarta $32.31 \%$ [5]. The WHO reports that every year rotavirus diarrhea causes more than 500,000 deaths of children under five years old in the world and unfortunatelly more than $80 \%$ of them occur in developing countries [6]. From January 2010 to December 2015, the average prevalence of rotavirus diarrhea per year for children to be hospitalized in four provinces in Indonesia was $47.5 \%$ [7].

Actions that can be taken to reduce morbidity and mortality due to an illness are immunization and maintaining environmental cleanliness [5]. The WHO recommends that rotavirus vaccine be included in national immunization programs and be prioritized, especially in South and Southeast Asian countries and sub-Saharan Africa. The Rotavirus vaccine in 2006 was included in the WHO's list of Essential Medicines, which included the safest and most effective medicines needed in the health systems [8]. The implementation of rotavirus vaccine in national health insurance programs reduces the burden of rotavirus diarrhea significantly. Brazil, El Salvador, Mexico, Nicaragua, Panama and Venezuela were the first group to include a rotavirus vaccine in their national vaccine program in 2006. By January 2011, fourteen countries in Latin America and Caribbean (LAC) had adopted retrovirus vaccine in their health system programs. The coverage of their rotavirus vaccination programs varies from 49\% - 98\%, of which Venezuela has the lowest and Nicaragua has the highest. All fourteen countries in LAC combine rotavirus and DTP3 vaccination schedules with a coverage range of 78\% - 99\% [9].

Even though the decision-making on implementation of the vaccine is in the hands of the health authorities, adequate knowledge and information regarding the burden of the disease 
and the benefit of vaccination might lead to successful immunization programs. This is because the high coverage of immunization is affected by high acceptance of community towards the immunization programs. One of the challenges of rotavirus vaccination in Indonesia is the lack of awareness and knowledge of the community towards the immunization. Therefore, it would be necessary to evaluate knowledge related to diseases and immunizations for new vaccines that will be included in the national health insurance program. Proper community knowledge regarding the disease and the immunization will help to avoid the absence of the children from the immunization and misunderstandings regarding the side-effects after the immunization [10]. In Yogyakarta province, the level of knowledge of health care providers related to rotavirus vaccine is low based on the results of previous studies that do not yet know the availability of rotavirus vaccine and consider that this disease is not dangerous while handling it well [11]. Therefore, increased and even distribution of knowledge related to rotavirus vaccine and rotavirus disease for both the health workers and the community are needed. The purpose of this study was to determine the factors that influence the public knowledge related to rotavirus vaccine that can influence the decision making to vaccinate their children.

\section{MATERIALS and METHODS}

\section{Study Design}

This study used an observational research design with a cross-sectional multi-center approach to parents who have children under 2 years and pregnant women in 5 provinces in Indonesia, namely, Province of Yogyakarta, Lampung, Central Kalimantan, Central Sulawesi, and West Java, in village integrated health center (Posyandu), Mother and Child Hospitals, Primary Healthcare Centers, daycare centers, prekindergarten and kindergarten schools.

\section{Population and Sample}

The number of samples was determined based on Lemeshow formula with a confidence level of $95 \%$ obtained by a total sample of 100 respondents for each province so that the total respondents for the 5 provinces in Indonesia were 500 respondents. Respondents were selected using convenience sampling techniques with inclusion criteria, namely parents who had children under the age of 2 years or pregnant women who lived in the study site. While the exclusion criteria were parents and pregnant women who were not willing to participate in research and who could not communicate well.

$$
n=\frac{Z_{1-\propto / 2}^{2} * P *(1-P)}{d^{2}}
$$

\footnotetext{
Description:

$\mathrm{n}=$ minimal sample size

$\mathrm{Z}_{1-\alpha / 2}^{2}=\mathrm{Z}$ score at $1-\alpha / 2$ confidence level $(\mathrm{Z}$ at $95 \%$ level is 1.96)

$\mathrm{P}=$ estimated proportion $(0,5)$

$\mathrm{d}=$ error (absolute) that can be tolerated precision $(0,1)$
}

\section{Study Instrument}

Study instrument was a questionnaire modified by researchers from some literature on sociodemographic factors (i.e. age, gender, education, marital status, employment, monthly income, monthly expenditure, number of dependents in the family, having health insurance) and the experience of respondents (i.e. never heard of the disease rotavirus diarrhea, have heard of the rotavirus vaccine, and have had rotavirus diarrhea). Respondents' knowledge questionnaire related to causes, symptoms, mode of transmission, age at risk, impact of the disease, prevention, treatment, benefits of vaccines, side effects, vaccination, vaccine doses [12], entered the government program [13] and contraindications [14]. The questionnaire was tested for validity using content validity by 3 experts in the pharmaceutical field and face validity by testing to 10 respondents.

\section{Data Analysis}

Data were analyzed descriptively and statistically. Knowledge variables consist of "Yes" and "No" answer choices, where the assessment uses the Guttman scale by answering "True $=1$ " and "False $=0$ " for positive questions and vice versa for negative questions. Knowledge score was converted from the number of correct answers into scale of 0 to 100. Descriptive analysis was used to determine the percentage of sociodemographic characteristics, experience and knowledge of respondents regarding rotavirus diarrheal disease and rotavirus vaccine. Statistical analysis used Mann Whitney different test to determine whether there were significant differences of knowledge score between sociodemographic characteristics and experience. The Mann Whitney test was used because the data were not normally distributed.

\section{Ethical Consideration}

This study was approved by the ethical commission of the Faculty of Medicine, Public Health, and Nursing at Gadjah Mada University, Indonesia, with KE/FK /1105/EC/2019 number. Respondents were given informed consent in advance as an agreement to participate in the study.

\section{RESULTS}

\section{Sociodemographic Characteristics, Respondents' Experiences and Knowledge Score}

Sociodemographic characteristics of 500 respondents as presented in Table 1 were as follows: the average age was 31 years old with the majority of middle adulthood ( $\geq 25$ years), mostly female, highly educated (high school and higher education), mostly married, mostly with average minimum wage, mostly having low monthly expenditure $(<$ IDR.2,218,000), having small number of dependents $(\leq 3)$, and mostly having health insurance. Table 1 also determined influence of the sociodemographic characteristics to knowledge score. Since the knowledge score was not normally distributed, to test the different of knowledge score, Mann Whitney test was used. There were significant differences in knowledge score based on the sociodemographic factors, namely age $(\mathrm{p}=0.05)$, education $(\mathrm{p}=0.045)$ and monthly expenditure $(\mathrm{p}=0.011)$. There were no significant differences of knowledge score based on respondent characteristics of sex, marital status, employment, monthly income, number of dependents, and health insurance ownership. 
Table 1. Overview of respondent's sociodemographic and knowledge score of rotavirus disease and vaccine

\begin{tabular}{|c|c|c|c|c|c|}
\hline \multirow{2}{*}{ Characteristics $(n=500)$} & \multirow{2}{*}{$\sum$ respondents } & \multirow{2}{*}{$\%$} & \multicolumn{3}{|c|}{ Knowledge } \\
\hline & & & Mean & Median & $p$-value* \\
\hline Age (Mean \pm SD, year) & $30.6 \pm 5.917$ & - & & & 0.05 \\
\hline Young Adults $(<25)$ & 68 & 13.6 & 74.89 & 76.92 & \\
\hline Intermediate Adult $(\geq 25)$ & 432 & 86.4 & 78.72 & 76.92 & \\
\hline Sex & & & & & 0.704 \\
\hline Male & 138 & 27.6 & 77.15 & 84.62 & \\
\hline Female & 362 & 72.4 & 78.6 & 76.92 & \\
\hline Education & & & & & 0.045 \\
\hline $\begin{array}{l}\text { Low (None/ Primary School, } \\
\text { Middle School) }\end{array}$ & 160 & 32 & 78.91 & 84.62 & \\
\hline $\begin{array}{l}\text { High (High School and Higher } \\
\text { Education) }\end{array}$ & 340 & 68 & 76.68 & 76.92 & \\
\hline Marital status & & & & & 0.096 \\
\hline Unmarried & 3 & 0.6 & 78.29 & 76.92 & \\
\hline Married & 497 & 99.4 & 64.1 & 69.23 & \\
\hline Employment & & & & & 0.13 \\
\hline Not working & 124 & 24.8 & 77.62 & 76.92 & \\
\hline Working & 376 & 75.2 & 79.96 & 84.62 & \\
\hline Monthly income & & & & & 0.216 \\
\hline Low (<IDR.2,218,000) & 227 & 45.4 & 77.06 & 76.92 & \\
\hline High ( $\geq$ IDR.2,218,000) & 267 & 53.4 & 79.17 & 84.62 & \\
\hline Monthly expenditure & & & & & 0.011 \\
\hline Low $(<$ IDR.2,218,000) & 305 & 61 & 77.15 & 76.92 & \\
\hline High $(\geq$ IDR.2,218,000) & 187 & 37.4 & 79.92 & 84.62 & \\
\hline Number of dependent & & & & & 0.854 \\
\hline Few $(\leq 3)$ & 340 & 68 & 78.61 & 76.92 & \\
\hline Many (>3), & 160 & 32 & 78.01 & 76.92 & \\
\hline Health insurance & & & & & 0.37 \\
\hline Have & 308 & 61.6 & 77.82 & 76.92 & \\
\hline Not have & 192 & 38.4 & 78.81 & 84.62 & \\
\hline
\end{tabular}

*Mann Whitney Test at 95\% confidence interval

Respondent's experiences related to rotavirus diarrheal disease and rotavirus immunization could be determined as fairly having heard of the disease, little of them having experiencing the disease, having heard the vaccine, and had been vaccinated. Among whom with the information, mostly received the information from health workers, friends and family members. Detailed information can be seen in Table 2 which also shows the influence of respondents' experience to knowledge score. There was significant difference of knowledge score based on respondents' experience of having heard about rotavirus diarrheal disease $(\mathrm{p}=0.000)$, having heard about rotavirus vaccine $(\mathrm{p}=0.000)$, and had been vaccinated with rotavirus vaccine $(\mathrm{p}=0.010)$, rotavirus diarrheal disease information source $(\mathrm{p}=0.034)$, and rotavirus vaccine information source $(\mathrm{p}=0.0001)$. Having experience of diarrheal diseases both from others or from their own children was not significantly affecting the respondents' knowledge ( $\geq$ $0.050)$. 
Table 2. Description of respondents' experiences and knowledge score of rotavirus disease and vaccine

\begin{tabular}{|c|c|c|c|c|c|}
\hline \multirow{2}{*}{ Characteristics $(\mathbf{n}=\mathbf{5 0 0})$} & \multirow{2}{*}{ n true } & \multirow{2}{*}{$\%$} & \multicolumn{3}{|c|}{ Knowledge } \\
\hline & & & Mean & Median & Pvalue \\
\hline Having heard rotavirus diseases & & & & & 0 \\
\hline Yes & 254 & 50.8 & 80.8 & 84.62 & \\
\hline No & 246 & 49.2 & 75.52 & 76.92 & \\
\hline Having had rotavirus diseases & & & & & 0.296 \\
\hline Yes & 111 & 22.2 & 80.25 & 76.92 & \\
\hline No & 389 & 77.8 & 77.62 & 76.92 & \\
\hline Having heard rotavirus vaccine & & & & & 0 \\
\hline Yes & 132 & 26.4 & 83.22 & 84.62 & \\
\hline No & 368 & 73.6 & 76.4 & 76.92 & \\
\hline Had been vaccinated with rotavirus & & & & & 0.01 \\
\hline Yes & 44 & 8.8 & 83.39 & 84.62 & \\
\hline No & 456 & 91.2 & 77.7 & 76.92 & \\
\hline Source of diseases information & & & & & 0.034 \\
\hline Health Workers, friends, family members & 166 & 33.2 & 81.65 & 84.62 & \\
\hline Mass media and others & 87 & 17.4 & 79.13 & 76.92 & \\
\hline Sources of vaccine information & & & & & 0.001 \\
\hline Health Workers, friends, family members & 81 & 16.2 & 85.19 & 84.62 & \\
\hline Mass media and others & 53 & 10.6 & 80.55 & 84.62 & \\
\hline
\end{tabular}

*Mann Whitney Test at 95\% confidence interval

Description of respondents' knowledge regarding rotavirus disease and vaccine

Description of respondents' knowledge regarding rotavirus disease and vaccine is presented in Table 3. The average knowledge score of 500 respondents was 76.92 (scale 0-100). Out of 13 questions related to rotavirus vaccine and disease, the majority of respondents gave correct answers. The respondent's knowledge value was still lacking (proportion of respondents with correct answer $<75 \%$ ) in the following items: the first treatment of rotavirus diarrhea $(72.8 \%)$, side effects of fever after immunization $(72.6 \%)$, rotavirus vaccination included in the national health insurance program $(31.6 \%)$, and rotavirus vaccination dose $(64.0 \%)$.

Table 3. Respondent's knowledge of rotavirus disease and vaccine.

\begin{tabular}{lcc}
\hline \multicolumn{1}{c}{ Question (n=500) } & Number of & \% \\
& correct answer \\
\hline 1) Rotavirus diarrheal disease caused by virus & 438 & 87.6 \\
2) Children with rotavirus diarrhea will experience fever, nausea, and lack of appetite & 467 & 93.4 \\
3) Rotavirus diarrheal disease can be transmitted from food and beverages & 409 & 436 \\
4) Infants under 5 years of age are more at risk of being infected with rotavirus & 87.2 \\
5) Rotavirus diarrheal disease can cause death in infants & 380 \\
6) Rotavirus diarrheal disease can be prevented by immunization & 456 \\
7) Rotavirus diarrheal disease can be treated with oral rehydration solution (ORS) & 364 \\
8) Rotavirus vaccine can be used to prevent rotavirus & 91.2 \\
9) After receiving an injection of rotavirus immunization, the child is likely to experience fever & 72.8 \\
\end{tabular}


10) Rotavirus immunization can be conducted in hospitals and clinics

467

11) Rotavirus immunization is given as much as two doses / $2 \mathrm{x}$ visits

12) Rotavirus immunization is included in the national health insurance program in Indonesia
93.4

\section{DISCUSSION}

This study was related to public knowledge about rotavirus vaccine and rotavirus diarrheal disease where public knowledge will affect the coverage of rotavirus vaccination in Indonesia while the vaccine has not been included in the national immunization program. Public knowledge related to rotavirus and rotavirus diarrhea showed that the majority of questions was answered correctly, indicating that the public knowledge in Indonesia regarding rotavirus and rotavirus diarrhea was quite good with a score of 76.92 from 100. However, there was still lack of public knowledge, particularly in terms of handling diarrhea with ORS, the emergence of fever effects after vaccination, doses in rotavirus vaccination, and the unavailability of rotavirus immunization program in the national program. The lack of community knowledge can be caused by the lack of comprehensive knowledge of information obtained at every opportunity, either immunization or visits to health services. Training provided to primary healthcare workers enabling them to identify and differentiate rotavirus clinically and to manage it is needed so that more people could receive health information from the health workers including information regarding rotavirus disease and vaccine [11]. Moreover, education is important in order to increase knowledge and change the habits of parents towards such health programs [13].

Knowledge in this study was associated with several factors, namely age, education level, monthly expenditure, have heard of rotavirus diarrheal disease and rotavirus vaccine, having received rotavirus vaccination, as well as information sources of rotavirus diarrheal disease and rotavirus vaccine. Also, age influenced knowledge which was in-line with the previous studies [15]. Previous studies have shown that higher education level significantly influences knowledge to conduct and receive better immunizations [16]. Also, father's knowledge increases with education level [17]. Expenditures per month as well as income per month were also important; since those with higher income will have higher knowledge [18]. This can be due to the large amount of parental expenditure per month that can be used in obtaining more adequate health services and health information.

The experience of having heard about rotavirus diarrheal disease and rotavirus vaccine influenced knowledge since information related to vaccine availability and its benefits gained from experience will increase public knowledge about rotavirus infection and vaccination. This information can be obtained from communication with health workers and education in all opportunities related to vaccination [19]. Information exposure to respondents who had been vaccinated should higher compared to those who have never been vaccinated. This is because someone who has been vaccinated knows more about the burden of disease, the benefits of vaccines, and the risks after vaccination. Rotavirus vaccination which can only be received in certain places makes a person to consider the benefits and risks. Previous experience of the sideeffects of a vaccine can also be related to knowledge about vaccines, where by experiencing the side-effects, parents will be more alert and eager to learn more about the vaccine [17]. Comparing sources of information from health workers and the mass media indicates that the information from health workers is considered to be truer. This would be important for training the health workers so that they should convey reliable information approved by the health authorities during vaccination campaigns [20].

In this study, factors that did not have significant influence on knowledge were gender, marital status, employment, monthly income, number of dependents, and insurance ownership. Gender has had a significant difference in knowledge in similar previous studies which have indicated that men have a higher knowledge score related to immunization; however, this was due to the fact that the majority of respondents were male [12]. Employment also had no effect and this probably happen because most respondents work environments were not related to health sectors. There was no relationship between monthly income and differences in the level of respondents' knowledge of rotavirus diarrheal disease and rotavirus vaccine. This can happen because not only highincome people can have access to knowledge. Knowledge can be obtained from anywhere, either from experience or information from communication. Other studies have shown that knowledge is increasing along with increasing monthly household income [21] and household income directly influences access to health care facilities in developing countries; hence it greatly influences one's attitude and knowledge [22].

In conclusion, we observed that public knowledge in 5 provinces of Indonesia regarding rotavirus diarrheal disease and rotavirus vaccine is quite good because the majority of the questions were answered correctly. However, there was still a lack of knowledge in terms of the unavailability of rotavirus immunization in the national immunization program of Indonesia. Factors that have an influence on knowledge were age, education, monthly expenditure, having heard of rotavirus diarrheal disease, having heard of rotavirus vaccine, having carried out rotavirus vaccination, rotavirus diarrhea information source, and rotavirus vaccine information source. The limitation of this study was the sampling technique which was a convenient, non-probability sampling technique and the number of study samples that cannot represent the entire population of Indonesia. However, this study is expected to give insight regarding knowledge of parents in Indonesia towards rotavirus diarrhea and vaccine. Future study should be expanded to larger area and sample size to precisely represent Indonesia population. 


\section{ACKNOWLEDGEMENT}

This work is part of Arie Dwi Pratiwi's thesis research at Master Program in Pharmacy Management, Faculty of Pharmacy, Gadjah Mada University, Indonesia. The authors are thankful to Faculty of Pharmacy UGM for funding assistance for research through the UGM Faculty of Pharmacy Research Grant in 2019 Number: 9.05.04/UN1/FFA1/SET.PIM/PT/2019.

\section{CONFLICT OF INTEREST}

The author declares no conflict of interest.

\section{REFERENCES}

1. John BM, Devgan A, Mitra B. Prevalence of rotavirus infection in children below two years presenting with diarrhea. Med J Armed Forces India. 2014;70:116-9. doi: 10.1016/j.mjafifi.2014.02.008

2. Chandran A, Fitzwater S, Zhen A, Santosham M. Prevention of rotavirus gastroenteritis in infants and children: rotavirus vaccine safety, efficacy, and potential impact of vaccines. Biologics. $2010 ; 4: 213-29$. Available from: https://www.ncbi.nlm.nih.gov/pmc/articles/PMC2921258/

3. Long SS, Pickering LK, Prober CG. Principles and Practice of Pediatric Infectious Disease. Elsevier Health Sciences; 2012. USA.

4. Organization WH. Meeting of the Strategic Advisory Group of Experts on immunization, October 2009 - conclusions and recommendations. Weekly Epidemiological Record = Relevé épidémiologique hebdomadaire. 2009;84:517-32.

5. Menkes RI. Permenkes Nomor 12 Tahun 2017 Tentang Penyelenggaraan Imunisasi. 2017. Available from: http://www.indonesianpublichealth.com/download-permenkes-nomor-12-tahun-2017-tentangpenyelenggaraan-imunisasi/

6. Junaid SA, Umeh C, Olabode AO, Banda JM. Incidence of rotavirus infection in children with gastroenteritis attending Jos university teaching hospital, Nigeria. Virology Journal. 2011;8:233. doi: 10.1186/1743-422X-8233

7. Mulyani NS, Prasetyo D, Karyana IPG, Sukardi W, Damayanti W, Anggraini D, et al. Diarrhea among hospitalized children under five: A call for inclusion of rotavirus vaccine to the national immunization program in Indonesia. Vaccine. 2018;36:7826-31. doi: 10.1016/j.vaccine.2018.05.031 8.Organization WH. WHO Rotavirus. WHO. 2018. Available from: http://www.who.int/immunization/diseases/rotavirus/en/

9. Center for Disease Control (CDC) 2011, „Progress in the introduction of rotavirus vaccine-Latin America and the Caribean, 2006-2010"e, Mortality and Morbidity Weekly Report, December, vol. 60, no. 47, pp. 1611-1614.

10. Organization WH. WHO Country decision making: introducing a new vaccine. 2015.2 Available from: http://www.who.int/entity/immunization/programmes_systems/policies_stra tegies/decision making/en/index.html

11. Seale H, Sitaresmi MN, Atthobari J, Heywood AE, Kaur R, MacIntyre $\mathrm{RC}$, et al. Knowledge and attitudes towards rotavirus diarrhea and the vaccine amongst healthcare providers in Yogyakarta Indonesia. BMC Health Serv Res . 2015;15. doi: 10.1186/s12913-015-1187-3

12. Ho HJ, Chan YY, Ibrahim MAB, Wagle AA, Wong CM, Chow A. A formative research-guided educational intervention to improve the knowledge and attitudes of seniors towards influenza and pneumococcal vaccinations. Vaccine. 2017;35:6367-74. doi: 10.1016/j.vaccine. 2017.10 .005

13. How CH, Phua See Chun P, Shafi F, Jakes RW. Parental knowledge, attitudes and perception of pneumococcal disease and pneumococcal conjugate vaccines in Singapore: a questionnaire-based assessment. BMC Public Health. 2016;16. doi: 10.1186/s12889-016-3597-5

14. Loubet P, Kernéis S, Groh M, Loulergue P, Blanche P, Verger P, et al. Attitude, knowledge and factors associated with influenza and pneumococcal vaccine uptake in a large cohort of patients with secondary immune deficiency. Vaccine. 2015;33:3703-8. doi: 10.1016/j.vaccine.2015.06.012

15. Awadh AI, Hassali MA, Al-lela OQ, Bux SH, Elkalmi RM, Hadi H. Does an educational intervention improve parents' knowledge about immunization? Experience from Malaysia. BMC Pediatr. 2014;14:254. doi: 10.1186/1471-2431-14-254

16. Konwea PE, David FA, Ogunsile SE. Determinants of compliance with child immunization among mothers of children under five years of age in Ekiti State, Nigeria. Journal of Health Research. 2018;32:229-36. doi: 10.1108/JHR-05-2018-024

17. Kara SS, Polat M, Yayla BC, Demirdag TB, Tapisiz A, Tezer H, et al. Parental vaccine knowledge and behaviours: a survey of Turkish families. East Mediterr Health J. 2018;24:451-8. doi: 10.26719/2018.24.5.451 18. Al-lela OQB, Bahari MB, Salih MR, Al-abbassi MG, Elkalmi RM, Jamshed SQ. Factors underlying inadequate parents' awareness regarding pediatrics immunization: findings of cross-sectional study in Mosul- Iraq. BMC Pediatr. 2014;14:29

19. Napolitano F, Ali Adou A, Vastola A, Angelillo IF. Rotavirus Infection and Vaccination: Knowledge, Beliefs, and Behaviors among Parents in Italy. Int J Environ Res Public Health. 2019 16. doi: 10.3390/ijerph16101807

20. Tabacchi G, Costantino C, Cracchiolo M, Ferro A, Marchese V, Napoli $\mathrm{G}$, et al. Information sources and knowledge on vaccination in a population from southern Italy: The ESCULAPIO project. Hum Vaccin Immunother. 2016;13:339-45. doi: 10.1080/21645515.2017.1264733

21. Rizwan A. Effect of Family Income on Knowledge, Attitude and Practices Regarding Breast Cancer and its Screening Methods Amongst Women of Lahore, Pakistan Article Info Abstract . ResearchGate. 2017. doi: 10.7324/JAPS.2017.70805

22. Peters DH, Garg A, Bloom G, Walker DG, Brieger WR, Rahman MH. Poverty and access to health care in developing countries. Ann N Y Acad Sci. 2008;1136:161-71. doi: 10.1196/annals.1425.011 